\title{
Manoeuvring forces on azimuthing podded propulsor model
}

\author{
Maciej Reichel \\ Ship Design and Research Centre \\ (CTO S.A.) Gdańsk
}

\begin{abstract}

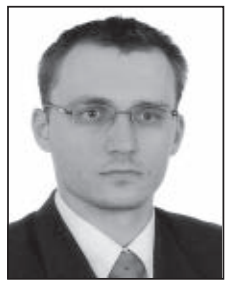

This paper presents the preliminary part of comprehensive manoeuvring open-water tests of a gas carrier model. The paper focuses on open water experiments with an azimuthing podded propulsor. The test program was carried out in the cavitation tunnel and the large towing tank of Ship Hydromechanics Division, Ship Design and Research Centre, Gdańsk. The pod was tested as a pushing unit with a $161.3 \mathrm{~mm}$ diameter propeller. Steering forces were measured in the range of advance coefficient from 0.0 to 0.8 combined with the range of deflection angles from $-45^{\circ}$ up to $+45^{\circ}$. Measurements on the pod without propeller were also performed. The experiment results are presented in the form of non-dimensional coefficients in function of advance coefficient and deflection angle. Analysis of the experimental results and the conclusions are presented.
\end{abstract}

Keywords : podded propulsors, open water experiments, manoeuvring forces.

\section{INTRODUCTION}

Podded propulsion, an integrated propulsion and steering system is known for nearly half a century [1].This type of propulsion has many advantages in comparison with traditional propeller-rudder set, e.g. vibration reduction and flexibility of internal design arrangement. But the most important advantage is its better manoeuvrability.

Although the good manoeuvring abilities of podded ships are known the manoeuvring characteristics are still not fully recognized. Standard experiments with free running propellers are not sufficient because the interaction effects between propeller and pod housing are very difficult to predict. Therefore it is advisable to carry out model tests with different podded drives to get data basis for the forces and moments at different steering angles $[2,3]$. It is important to collect data for many possible pod configurations, e.g. push, pull, single or twin set.

The knowledge of the forces and moments acting on the propeller and podded drive at different steering angles is necessary for design and optimisation of azimuthing propulsion systems. Also information about wake velocity field is important in design aft part of the hull and possibly also skegs or additional rudders [4].

\section{MODEL OF THE PODDED DRIVE}

Tab. 1. Main data of $P 447$ propeller model.

\begin{tabular}{|c|c|c|c|}
\hline & Symbol & Unit & Model \\
\hline Propeller diameter & $\mathrm{D}$ & $\mathrm{mm}$ & 161.3 \\
\hline Pitch at $\mathrm{r} / \mathrm{R}=0.7$ & $\mathrm{P}$ & $\mathrm{mm}$ & 126.0 \\
\hline Pitch ratio at $\mathrm{r} / \mathrm{R}=0.7$ & $\mathrm{P} / \mathrm{D}$ & - & 0.785 \\
\hline
\end{tabular}

\begin{tabular}{|c|c|c|c|}
\hline $\begin{array}{c}\text { Expanded blade area } \\
\text { ratio }\end{array}$ & $\mathrm{A}_{\mathrm{E}} / \mathrm{A}_{0}$ & - & 0.550 \\
\hline Hub ratio & $\mathrm{d}_{\mathrm{h}} / \mathrm{D}$ & - & 0.219 \\
\hline Number of blades & $\mathrm{z}$ & - & 4 \\
\hline Direction of rotation & & - & right \\
\hline Revolutions per minute & $\mathrm{n}$ & - & 900 \\
\hline
\end{tabular}

Tab. 2. Main data of POD 09 pod model.

\begin{tabular}{|c|c|c|c|}
\hline & Symbol & Unit & Model \\
\hline Gondola length & $\mathrm{l}_{\mathrm{G}}$ & $\mathrm{mm}$ & 106.2 \\
\hline Gondola diameter & $\mathrm{d}_{\mathrm{G}}$ & $\mathrm{mm}$ & 61.6 \\
\hline $\begin{array}{c}\text { Strut height (from } \\
\text { propeller shaft) }\end{array}$ & $\mathrm{h}$ & $\mathrm{mm}$ & 97.6 \\
\hline Strut length & $\mathrm{c}_{0.7}$ & $\mathrm{~mm}$ & 53.5 \\
\hline
\end{tabular}

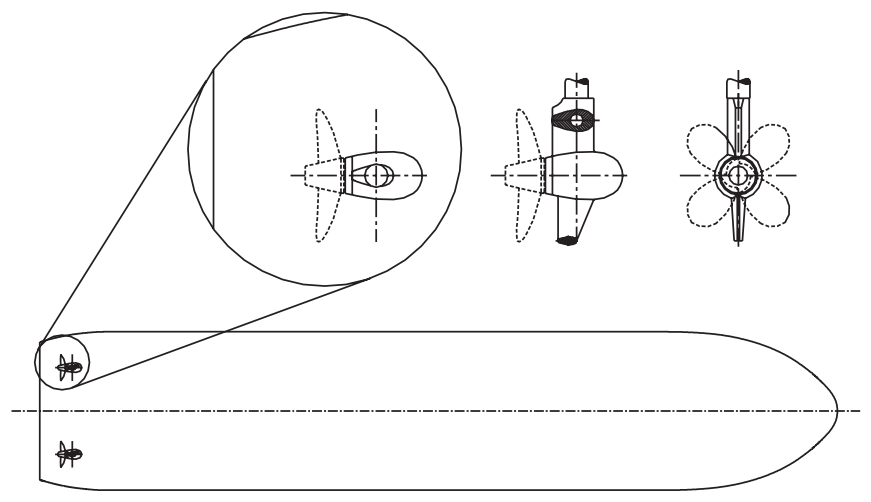

Fig. 1. Arrangement of pod propulsors and pod geometry 


\section{TEST FACILITY AND PLAN OF THE EXPERIMENT}

The open water tests were carried out in the cavitation tunnel and in the large towing tank of Ship Hydromechanics Division, Ship Design and Research Centre in Gdańsk, (OHO-CTO).

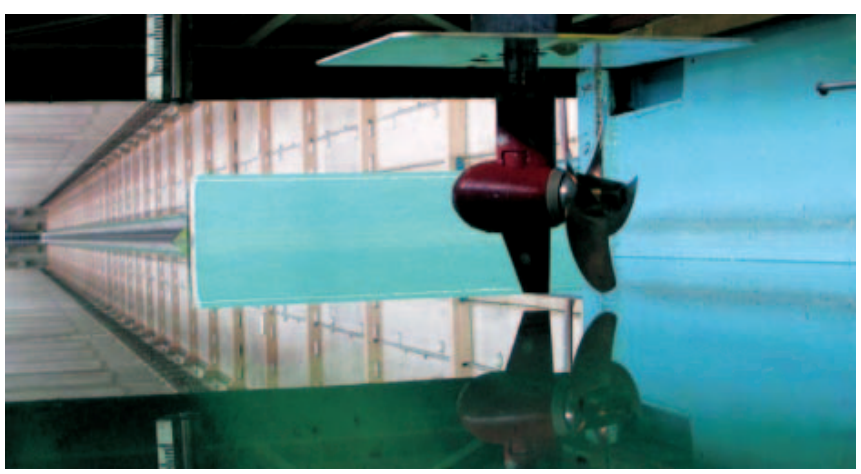

Fig. 2. Podded drive in the OHO-CTO large towing tank before tests

Measurements were conducted at the constant number of revolutions equal to $900 \mathrm{rpm}$. The carriage velocities were so established as to obtain advance coefficient of $0.2 ; 0.4 ; 0.6 ; 0.8$. The experiments were performed for thirteen deflection angles in the range from $-45^{\circ}$ up to $+45^{\circ}$, with the step of $5^{\circ}$ from $-15^{\circ}$ to $+15^{\circ}$ and 10 within the rest of the range. Forces on the bare pod, i.e. without propeller, were also measured. The positive deflec-

tion angle and directions of forces are shown in Fig.3.
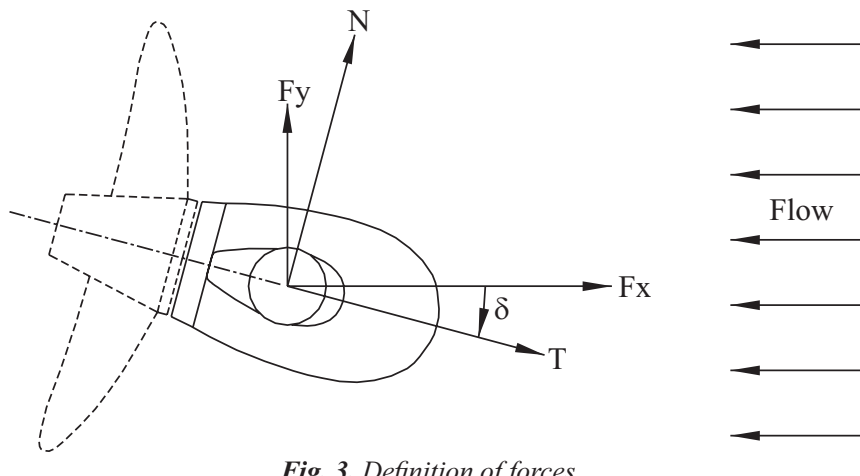

\section{RESULTS}

All the results are presented in the traditional non-dimensional form by applying the following formulae :

- Advance coefficient $\mathrm{J}=\frac{\mathrm{U}_{\mathrm{ref}}}{\mathrm{nD}}$

$\Rightarrow$ Longitudinal force coefficient $\quad K_{F X}=\frac{F_{X}}{\rho n^{2} D^{4}}$

- Transverse force coefficient $\quad K_{F Y}=\frac{F_{Y}}{\rho n^{2} D^{4}}$

- Thrust coefficient

$$
\mathrm{K}_{\mathrm{T}}=\frac{\mathrm{T}}{\rho \mathrm{n}^{2} \mathrm{D}^{4}}
$$

- Normal force coefficient

$$
K_{N}=\frac{N}{\rho n^{2} D^{4}}
$$

- Torque coefficient

$$
K_{Q}=\frac{Q}{\rho n^{2} D^{4}}
$$

where :

$$
\begin{aligned}
& U_{\text {ref }} \text { - inflow velocity } \\
& \delta \text { - deflection angle } \\
& \rho \text { - water density } \\
& n \text { - propeller revolutions } \\
& D \text { - propeller diameter. }
\end{aligned}
$$

The thrust and normal force were calculated by applying the following transformation from the towing tank coordinate system to the propulsor coordinate system :

$$
\left[\begin{array}{c}
\mathrm{T} \\
\mathrm{N}
\end{array}\right]=\left[\begin{array}{cc}
\cos \delta & -\sin \delta \\
\sin \delta & \cos \delta
\end{array}\right]\left[\begin{array}{l}
\mathrm{F}_{\mathrm{X}} \\
\mathrm{F}_{\mathrm{Y}}
\end{array}\right]
$$

In Fig.4 the open water characteristics for the P447 propeller are shown. The characteristics were measured on the model without pod housing and only for straight flow.

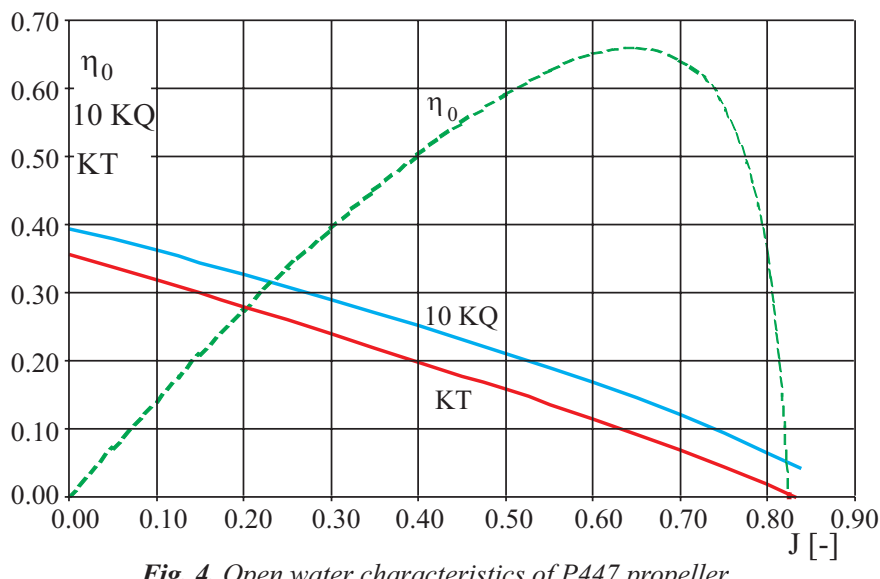

Results of the measurements of the forces on the bare pod are presented in the figures below. The experiment was made for one advance coefficient equal to 0.6 and for five deflection angle values : $\pm 45^{\circ}, \pm 10^{\circ}, 0^{\circ}$.

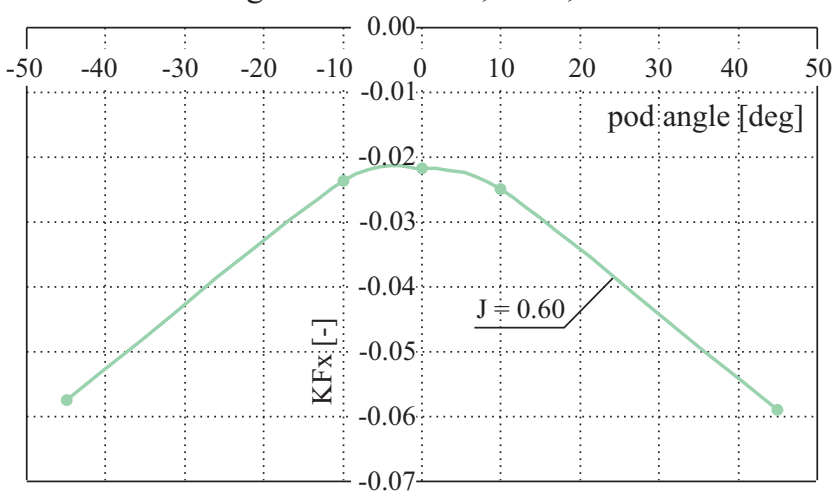

Fig. 5. Longitudinal force coefficients vs. deflection angle of bare pod.

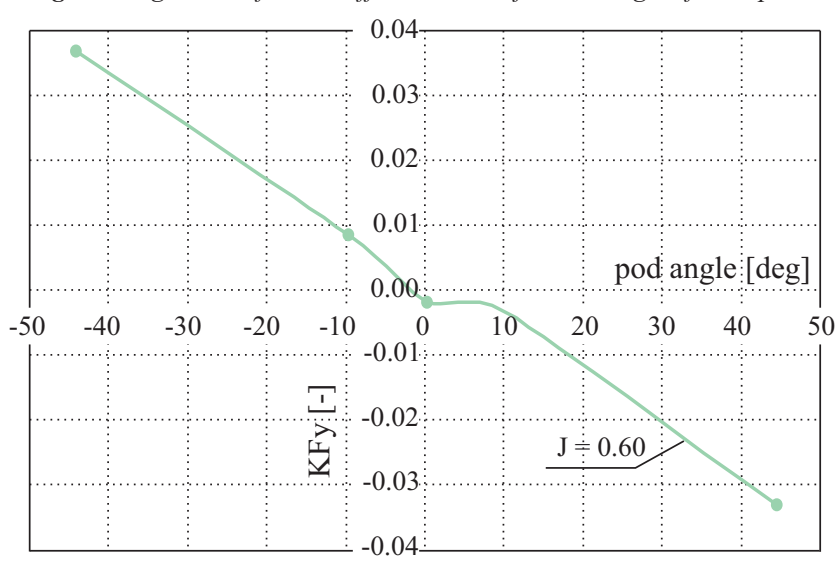

Fig. 6. Transverse force coefficients vs. deflection angle of bare pod. 


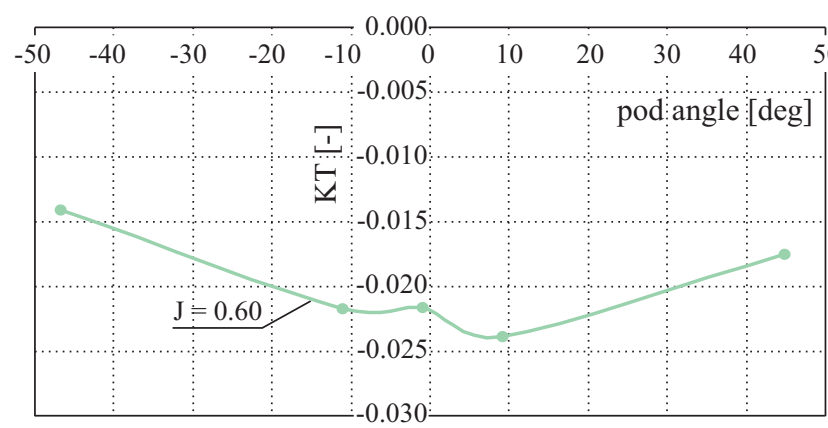

Fig. 7. Thrust force coefficients vs. deflection angle of bare pod

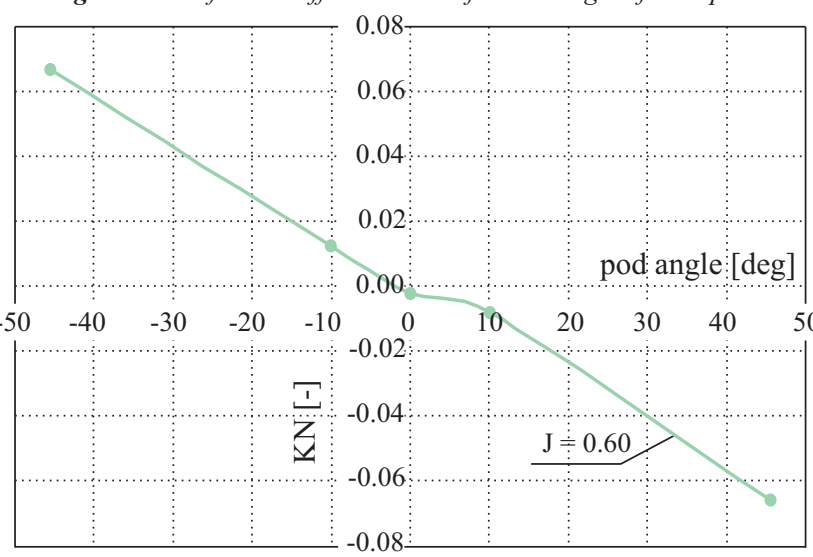

Fig. 8. Normal force coefficients vs. deflection angle of bare pod

The subsequent figures show results for the podded drive with right-handed $\mathrm{P} 447$ propeller.

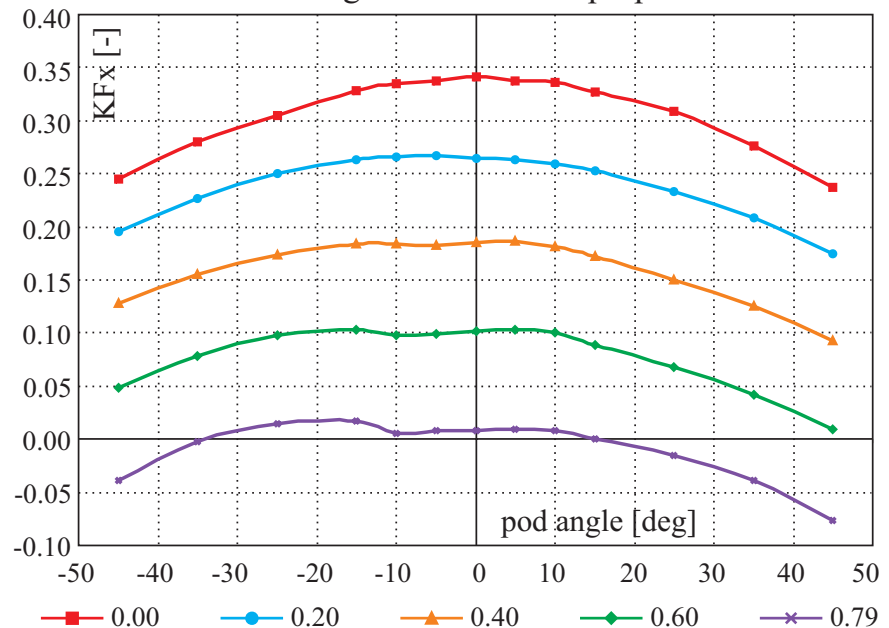

Fig. 9. Longitudinal force coefficient vs. deflection angle .

$\star$ the longitudinal force coefficients show parabolic dependence on deflection angle, with the tendency to reduction for higher angles. For positive deflection angles the reduction of longitudinal force coefficients is higher than for negative ones (Fig.9)

$\star$ the transverse force coefficients are approximately linear in function of deflection angles, with deviation to higher values for larger deflection angles and advance coefficients. In the vicinity of $15^{\circ}$ deflection angle a little disturbance is observed (Fig.10)

$\star$ the thrust coefficients depend strongly on deflection angles and propeller loading. For both steering directions the thrust is increasing but its increase is visibly stronger for negative deflection angles (Fig.11)

$\star$ the normal force coefficients behave like the transverse force coefficients, i.e. approximately linear in function of
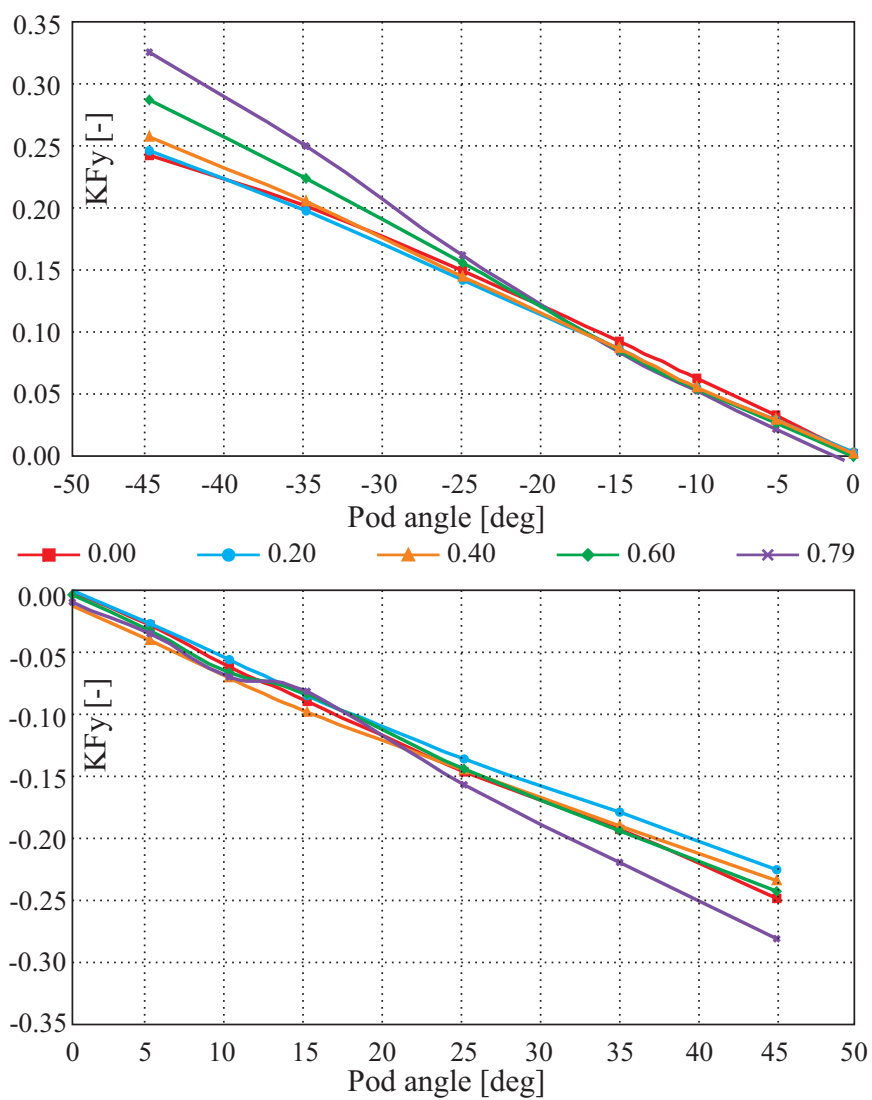

Fig. 10. Transverse force coefficient vs. deflection angle

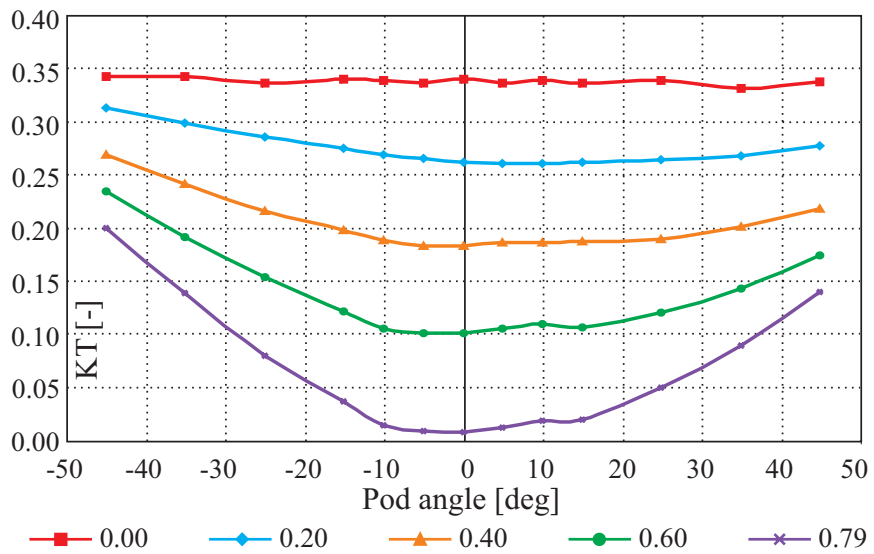

Fig. 11. Thrust coefficient vs. deflection angle

deflection angle, however with a faster increase for higher advance coefficients. Like in the case of the transverse force coefficients a little disturbance is visible in the vicinity of $15^{\circ}$ deflection angle (Fig.12).

To calculate the coefficients of forces in function of advance coefficient the following formulae were applied :

$$
\mathrm{U}_{\text {ref }}=\mathrm{U}_{\mathrm{CAR}} \cdot \cos \delta
$$

where :

$\mathrm{U}_{\mathrm{CAR}}$ - towing carriage velocity.

for smaller pod deflection angles the longitudinal force coefficients are decreasing faster than for higher ones. The nature of the dependence is similar to that of a classic propeller (Fig.13)

for small pod deflection angles up to $15^{\circ}$, the transverse force coefficients depend almost linearly on advance co- 

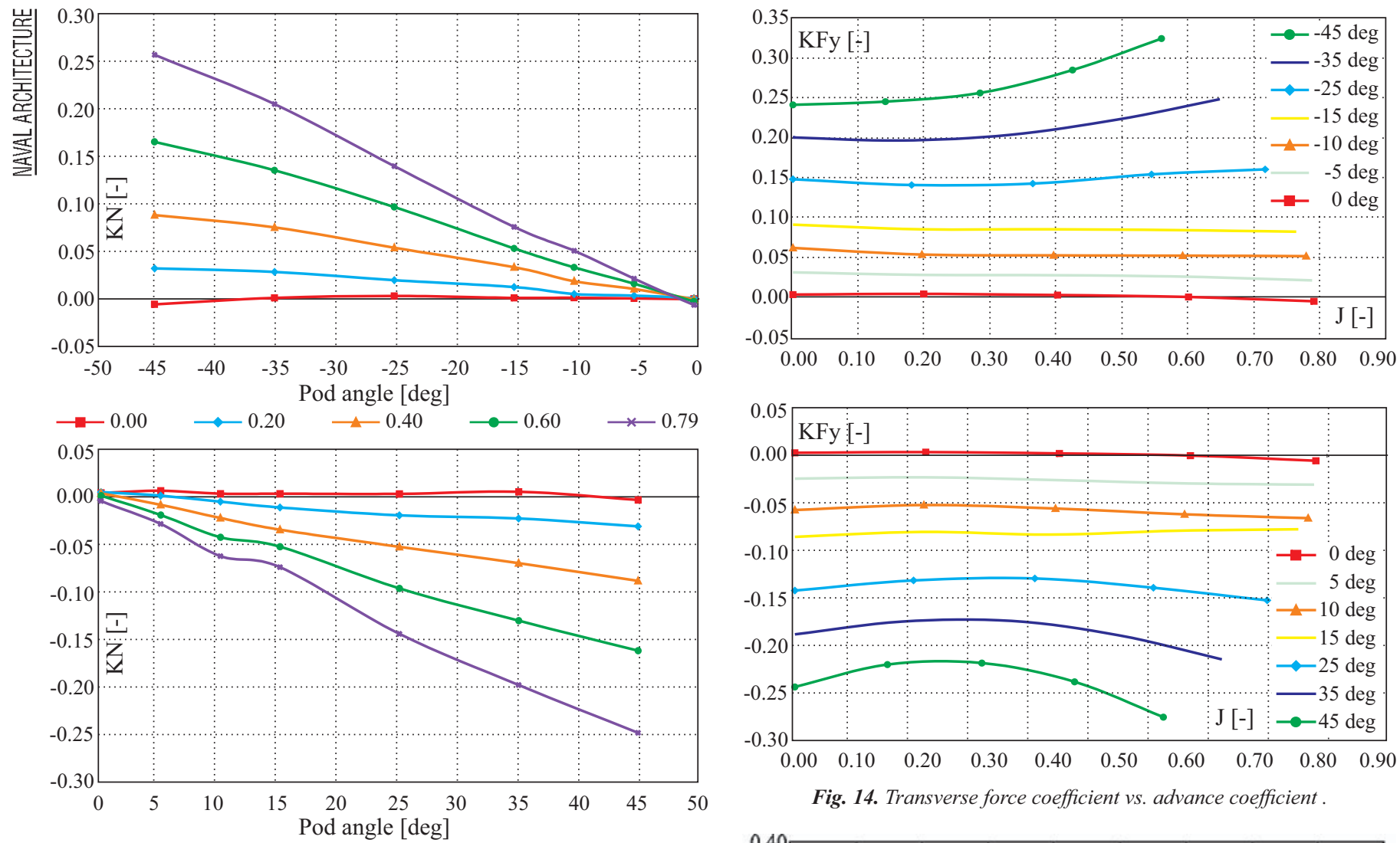

Fig. 14. Transverse force coefficient vs. advance coefficient .

Fig. 12. Normal force coefficient vs. deflection angle .
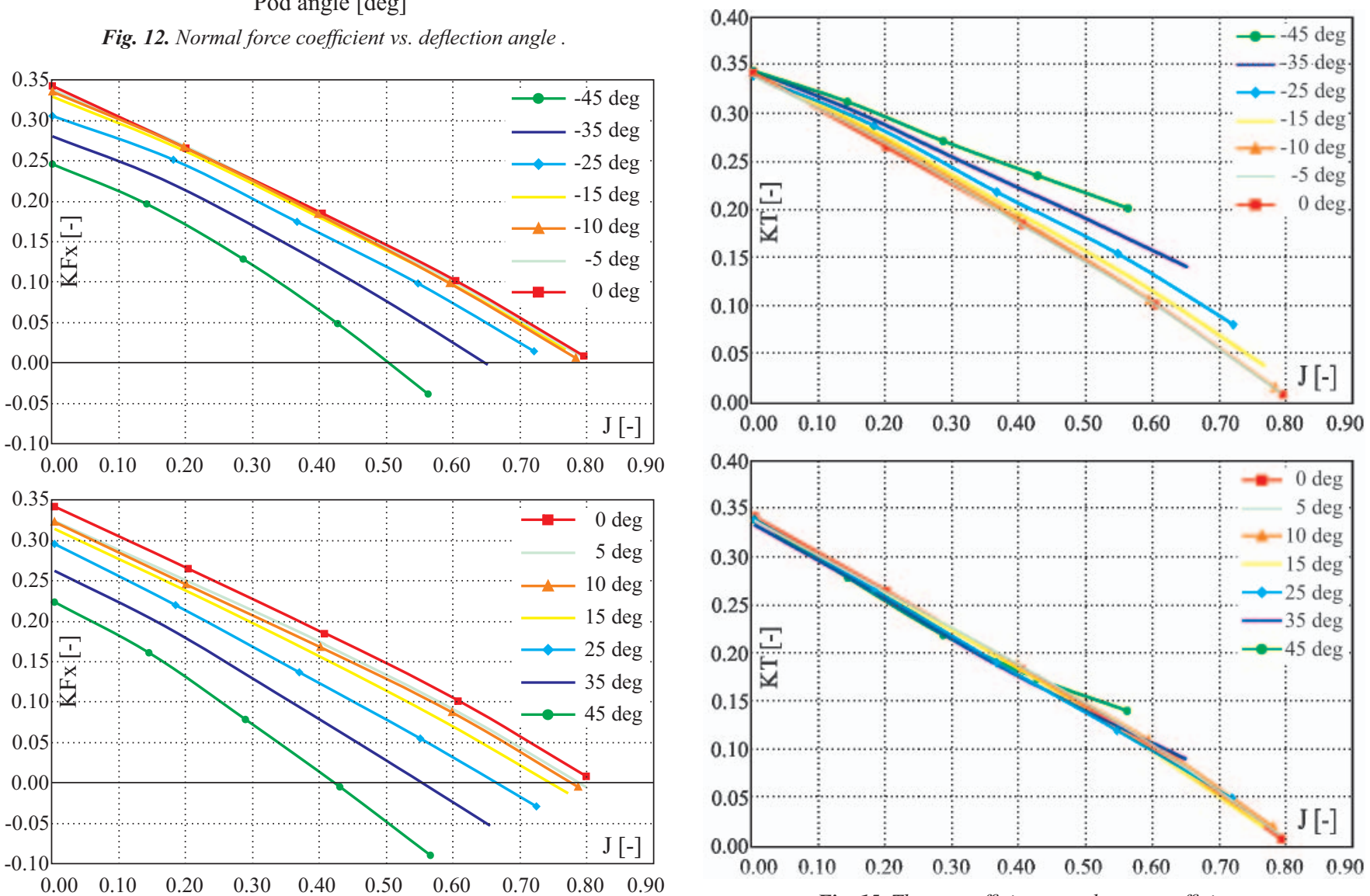

Fig. 13. Longitudinal force coefficient vs. advance coefficient .

efficient; for higher angles the dependence is changing to parabolic one (Fig.14)

$\star$ the thrust coefficients in function of advance coefficient are decreasing but for positive pod deflection angles the decreasing is independent on deflection angle value (Fig.15)

$\star$ the normal force coefficients show tendency to change their character from linear to parabolic for higher pod deflection angles in function of advance coefficient (Fig.16)

Fig. 17 introduced to summarize the content of the previous figures shows proportion of thrust force and normal force 
between positive and negative pod angle. The value of $100 \%$ represents the thrust force and normal force for the positive direction of pod angle. For the negative pod deflection angles the absolute value of normal force was used.
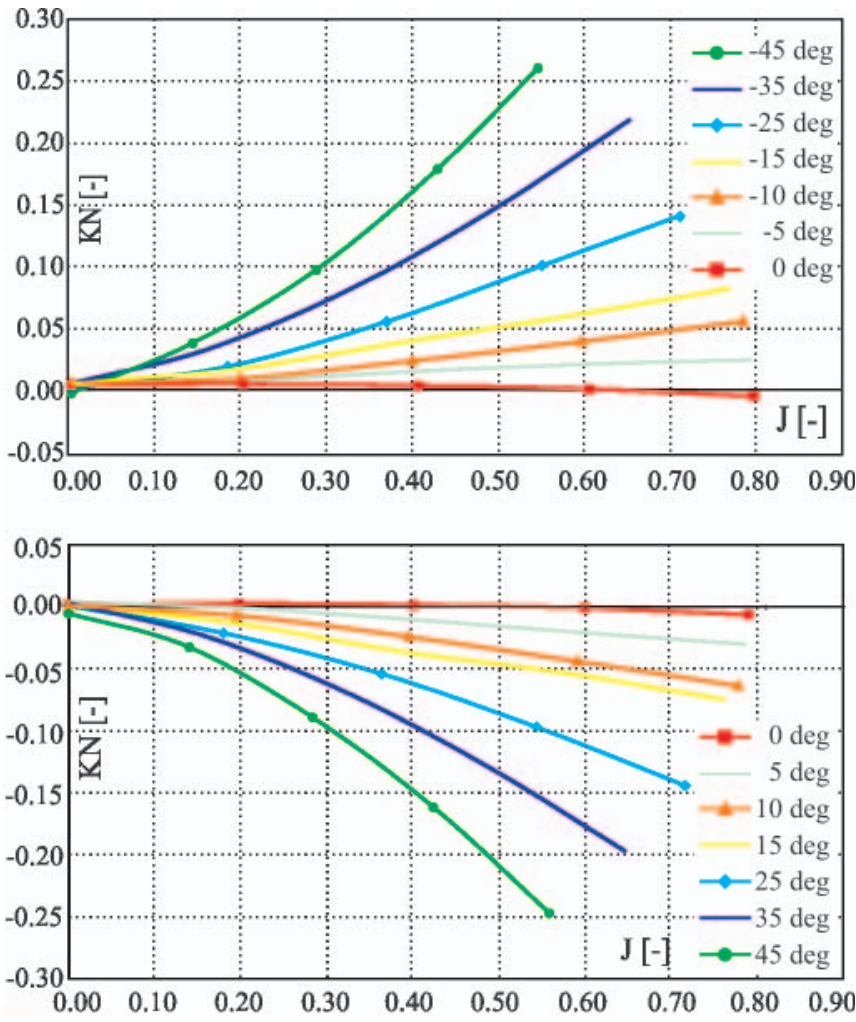

Fig. 16. Normal force coefficient vs. advance coefficient
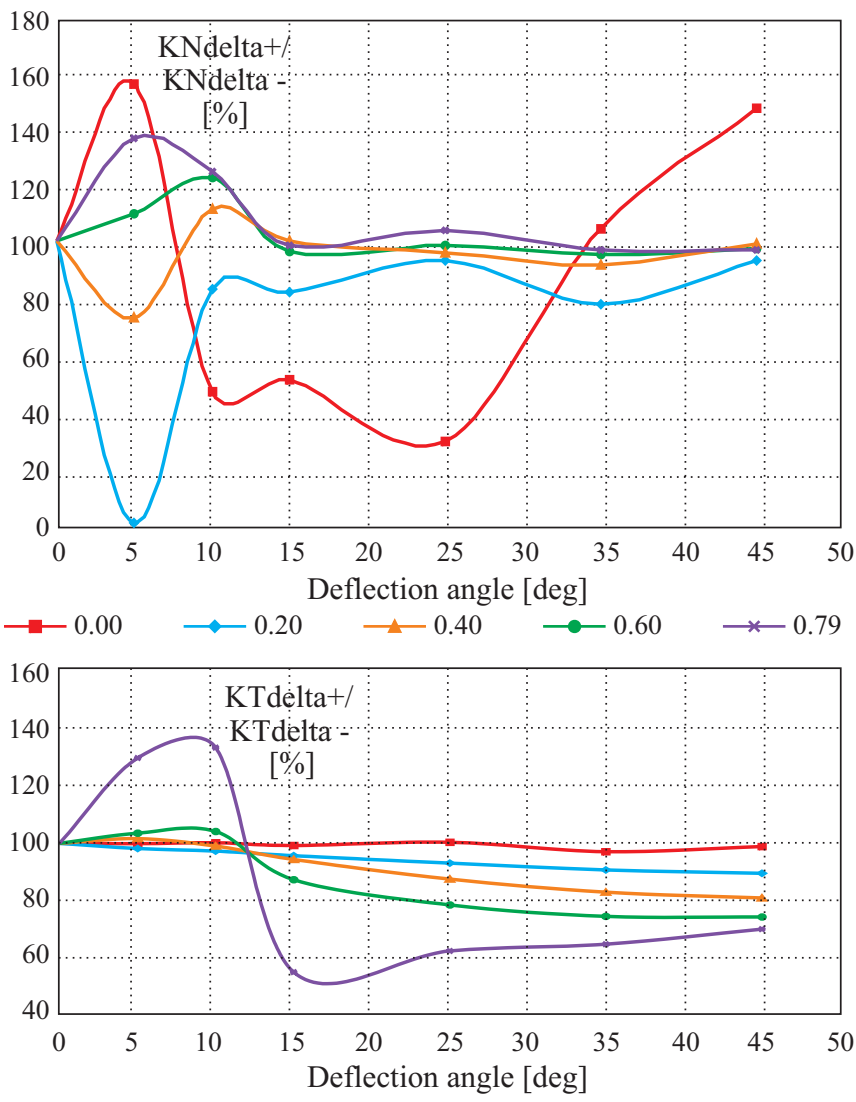

Fig. 17. Interdependence between $K T$ and $K N$ for positive and negative deflection angles

$\star$ the ratio of normal force coefficients shows difficult dependence for small deflection angles, for angles higher than $15^{\circ}$ the relationship shows tendency to be linear in the vicinity of in the range of $80-100 \% \frac{\mathrm{KN}_{\delta+}}{\mathrm{KN}_{\delta-}}$. The exception to the tendencies is visible at $\mathrm{J}=0.00$. For small advance coefficients the normal force coefficient ratio is smaller than for higher ones

$\star$ the ratio of the thrust coefficients shows tendency to increase for small pod angles up to $10^{\circ}$, and to decrease for higher deflection angles. This tendency is more visible for higher advance coefficients.

\section{CONCLUSIONS}

To summarize results obtained from the towing tank tests the following conclusions may be presented :

the presented results clearly show the typical hydrodynamic characteristics of azimuthing podded propulsion

the asymmetries in values of the force coefficients for positive and negative deflection angles are due to the influence of the direction of propeller rotation (to the right)

with positive pod angle a negative normal force is produced and vice versa, which results in a destabilizing moment tending to increase the turn rate

the increase of thrust coefficients for higher deflection angles is induced by reduction of axial inflow velocity which involves reduction of advance coefficient

for deflection angles larger than $15^{\circ}$ the thrust and normal force coefficients are from $10 \%$ to $30 \%$ smaller than for the corresponding positive deflection angles, which is caused due to the interaction between right - handed propeller and podded drive.

\section{Acknowledgments}

The author would like to express his gratitude to the Ship Hydromechanics Division, Ship Design and Research Centre, Gdańsk, especially to Mr. Wojciech Górski, the head of the Division.

\section{NOMENCLATURE}

$\mathrm{A}_{\mathrm{E}} / \mathrm{A}_{0}$ - expanded blade area ratio

$c_{0.7} \quad$ - strut length

$\mathrm{d}_{\mathrm{G}} \quad$ - gondola diameter

$\mathrm{d}_{\mathrm{h}} / \mathrm{D}$ - hub ratio

D - propeller diameter

Fx - longitudinal force

Fy - transverse force

h $\quad$ - strut height (from propeller shaft)

J - advance coefficient

$\mathrm{K}_{\mathrm{Fx}}$ - longitudinal force coefficient

$\mathrm{K}_{\mathrm{FY}}$ - transverse force coefficient

$\mathrm{K}_{\mathrm{N}}$ - normal force coefficient

$\mathrm{K}_{\mathrm{O}} \quad$ - torque coefficient

$\mathrm{K}_{\mathrm{T}}^{\mathrm{Q}}$ - thrust coefficient

$1_{\mathrm{G}} \quad$ - gondola length

$\mathrm{n}$ - revolutions per minute

$\mathrm{N}$ - normal force

$\mathrm{P} \quad$ - pitch at $\mathrm{r} / \mathrm{R}=0.7$

$\mathrm{P} / \mathrm{D}$ - pitch ratio at $\mathrm{r} / \mathrm{R}=0.7$

Q - torque

$\mathrm{T}$ - thrust force

$\mathrm{U}_{\mathrm{CAR}}$ - carriage velocity

$\mathrm{U}_{\text {ref }}^{\text {CAR }}$ - inflow velocity

z $\quad$ - number of blades

$\delta \quad$ - pod angle

$\rho \quad$ - water density

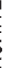




\section{BIBLIOGRAPHY}

1. Van Terwisga T., Quadvlieg F., Valkhof H.: Steerable propulsion units: hydrodynamic issues and design consequences. $80^{\text {th }}$ anniversary of Schottel GmbH \& Co., 2001

2. Grygorowicz M., Szantyr J.A. : Open water experiments with two pod propulsor models. First International Conference on Technological Advances in Azimuthing Podded Propulsion (T-POD), Newcastle-upon-Tyne, 2004

3. Heinke H. J.: Investigations about forces and moments at podded drives. First International Conference on Technological Advances in Azimuthing Podded Propulsion (T-POD), Newcastle-upon-Tyne, 2004

4. Stettler J. W., Hover F.S., Triantafyllou M.S.: Preliminary results of testing on the dynamics of an azimuthing podded propulsor relating to vehicle maneuvering. Naval Engineering And Research Consortium, Massachusetts Institute of Technology, 2004.

\section{CONTACT WITH THE AUTHOR}

Maciej Reichel, D.Sc., Eng.

Ship Hydromechanics Division,

Ship Design and Research Centre - Stock Company (OHO - CTO)

Szczecińska 65

80-392 Gdańsk, POLAND

e-mail : maciej.reichel@cto.gda.pl

\section{Conference
REGIONAL GROUP
of the Section
on Exploitation Foundations}

On 18 January 2007 at Mechanical Faculty, Gdynia Maritime University, was held a scientific seminar of the Regional Group of the Section on Exploitation Foundations, Machine Building Committee, Polish Academy of Sciences (PAS).

The Seminar program contained presentation of six papers elaborated by scientific workers of the Faculty, as follows :

* Professor Jan Kazimierz Włodarski - 55 years of activity in the field : construction and operation of machines - by R. Cwilewicz and K. Witkowski

* On failures of piston-cylinder system of ship internal combustion engines - by J. K. Włodarski

* Assessment of influence of indicator channel and its dimensions on results of pressure measurements in engine cylinder - by W. Gałecki

* Investigations of ageing process of lubricating oils in trunk-piston engines - by A. Młynarczak

* Possibilities of diagnosing selected failures of injection devices of self-ignition engines on the basis of indicator diagram run - by R. Pawletko

- A new concept of building ship power plant simulators with the use of $3 D$ visualization - by L. Tomczak

After interesting discussion the Seminar participants visited scientific laboratories of the University.

\section{Jubilee of $50^{\text {th }}$ Anniversary}

On 30 June - 1 July 2006 the Experimental Centre for Ship Model Tests in Open Waters, Faculty of Ocean Engineering and Ship Technology, Gdańsk University of Technology, celebrated $50^{\text {th }}$ anniversary of its rich activity.

The Centre has been established due to initiative of Prof. Lech Kobyliński, Head of the then Ship Theory Department, Faculty of Ocean Engineering and Ship Technology, Gdańsk University of Technology. All the matter have started from hydrofoils. In 1955 a small, $4.5 \mathrm{~m}$ long, hydrofoil was built in the Department, whose first trials was conducted on Motława river, and simultaneously the Department was assigned to conduct realization of a project for development of hydrofoils, in which Polish Navy was interested. In that time Prof. Kobyliński decided to organize the Experimental Centre on the area of a deserted water sport centre by Jeziorak lake in Iława. In summer 1956 just in this place the research trials on hydrofoils started again. Results of the research on a few manned models as well as relevant theoretical elaborations resulted in the mastering of design principles of such floating units.

In 1965 in Wisła Shipyard was built a passenger hydrofoil for 76 persons, which was operated by Szczecin Coastal Shipping Co till 1968, and after modernization - by Polish Navy on the Gdynia - Hel route till 1993. Finally the activity in that area was ended in the 1960s when several hydrofoils were purchased in Soviet Union. Apart from hydrofoils, model tests started in the range of resistance, propulsion, propellers, manoeuvrability, sea-keeping qualities of conventional ships, and also of river pushers and push-trains, hovercrafts and fast boats; also various special investigations were carried out there.

Results of the tests were implemented by shipyards' ship design offices, shipping companies and classification institutions, as well as they were presented at many scientific conferences in Poland and abroad.

25 years ago, also in Iława, has started the first ship manoeuvring training course for ship masters, carried out with the use of large manned ship models, that contributed

to arranging the Training Centre by the Silm lake.

These services and research carried out in Iława have initiated organization of symposia on ship hydromechanics in Poland, and later - also symposia on ship manoeuvrability.

Hence it is not an exaggeration to state that the Centre in question deserves the name of the "cradle" of Polish ship hydromechanics.

In present, the Centre fulfils also the role of the base for international student scientific camps, and permanently, the student training base for yachting sports. 